\title{
Metallophytes for organic synthesis: towards new bio-based selective protection/deprotection procedures
}

\author{
Claire M. Grison • Alicia Velati • Vincent Escande • \\ Claude Grison
}

\begin{abstract}
We propose for the first time using metal hyperaccumulating plants for the construction of a repertoire of protection and deprotection conditions in a concept of orthogonal sets. Protection of alcohol, carbonyl, carboxyl, and amino groups are considered. The ecocatalysts derived from metal-rich plants allow selective, mild, eco-friendly, and efficient protection or deprotection reactions. The selectivity is controlled by the choice of the metal, which is hyperaccumulated by the metallophyte.
\end{abstract}

Keywords Ecocatalysis $\cdot$ Bio-based chemistry $\cdot$ Protecting groups $\cdot$ Metal hyperaccumulating plants $\cdot$ Phytoextraction

\section{Introduction}

Transitioning from fossil carbon to alternative green carbon is an essential objective of the current bio-sciences. In the area of bio-based chemistry, using raw materials derived from

\section{M. Grison}

Institut de Chimie Moléculaire et des Matériaux d'Orsay, Université Paris Sud, Rue du Doyen Georges Poitou, 91405 Orsay Cedex, France

\author{
A. Velati $\cdot$ V. Escande $\cdot$ C. Grison $(\bowtie)$ \\ Laboratory of Bioinspired Chemistry and Ecological Innovations \\ FRE CNRS UM2 Stratoz 3673, Cap Alpha, Avenue de l'Europe, \\ 34830 Clapiers, France \\ e-mail: claude.grison@cnrs.fr \\ V. Escande \\ ADEME, 20 av. du Grésillé, BP90406, 49004 Angers, France
}

biomass is a very important and challenging objective for the production of platform commodity chemicals. Intense efforts and progresses have been realized in the development of attractive processes of the transformation of feedstocks into basic chemicals. However, a gap still persists between efforts to boost the bio-based synthesis of basic and commodity chemicals and the preparations of intermediate, fine, complex, and high value-added specialty chemicals. The use of natural resources, such as oligosaccharides, glycopeptides, glycolipids, peptides, and nucleotides, raises the question of the polyfunctional molecules for the design of complex molecules. It is a central problem in fine organic synthesis. The topic of functional group incompatibility is little studied in eco-friendly synthesis. Bio-inspired chemistry cannot totally avoid protection/deprotection steps, because they are necessary to develop access to complex molecules. It is therefore interesting to revisit temporary modifications using blocking or protecting groups with an eco-friendly approach.

Considering the chemo-, regioselectivity, and mildness of our ecocatalysts (Escande et al. 2013a, b, 2014; Grison et al. 2013; Grison and Escarre 2011; Grison and Escande 2012, 2013, 2014; Losfeld et al. 2012a, b, c), we propose for the first time using metal-hyperaccumulating plants for the construction of a repertoire of protection and deprotection conditions in a concept of orthogonal sets. The choice of the functional groups described is based on their utility in conversion of renewable biomass. The selectivity, protection, and cleavage conditions are described.

\section{Materials and methods}

Ecocatalyst preparation

The selection of hyperaccumulator plants was undertaken in the context of our ongoing phytoremediation programs. $\mathrm{Zn}$ - 
Table 1 Metallophytes species and derived ecocatalysts

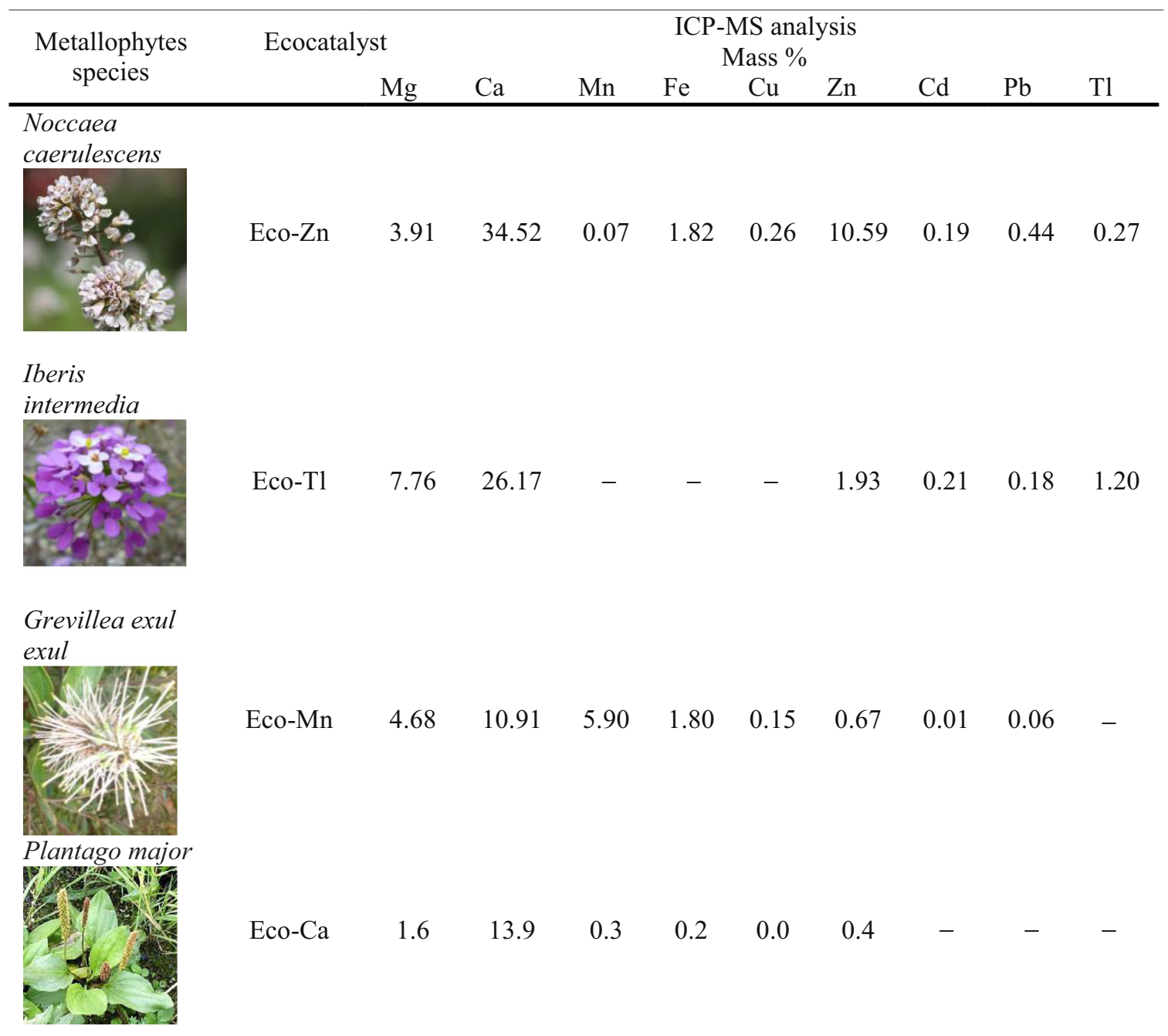

hyperaccumulating leaves were derived from Noccaea caerulescens. Tl-hyperaccumulating leaves were derived from Iberis intermedia. They were collected from plants growing on the Les Avinières mine site at Saint-Laurent-Le-Minier (Gard) in the Mediterranean climate region of southern France.

Mn-hyperaccumulating leaves were derived from Grevillea exul spp. exul. They were collected from plants growing in the southern province of the subtropical Pacific island of New Caledonia.

Leaves rich in $\mathrm{Ca}$ were derived from Plantago major. They were collected from plants growing on Montpellier (Hérault) in the Mediterranean climate region of southern France.

Leaves were harvested before flowering, air-dried, and grounded. In the case of ecocatalysis (Eco)-Zn, Eco-Mn, and Eco-Ca catalysts, the obtained solid (150 g) was calcinated at $400{ }^{\circ} \mathrm{C}$ for $5 \mathrm{~h}$, and the resulting powder $(14.8 \mathrm{~g})$ was added to $1 \mathrm{~L}$ of hydrochloric acid $(\sim 1 \mathrm{M})$ solution. For the Eco-Tl catalyst, the solid was reacted within $65 \mathrm{~mL}$ of concentrated nitric acid. The solution was heated at $60{ }^{\circ} \mathrm{C}$ and stirred for $2 \mathrm{~h}$. The reaction mixture was then filtered on celite. Resulting ecocatalysts were stored under nitrogen atmosphere until the next laboratory period. Purification steps are not mandatory in our process inductively coupled plasma mass spectrometry (ICP-MS) was used to determine the composition of the various ecocatalysts obtained. Results are summarized in Table 1.

Protection/deprotection by ecocatalysis

\section{Chemicals}

Reagents and solvents were purchased from commercial sources (Aldrich, Acros, Merck, Fluka, and VWR International). Reagents were used without further purification unless otherwise noted. Pyridine, acetonitrile, and triethylamine were distilled under calcium hydride. All reactions were performed under argon (or nitrogen) and stirring unless otherwise noted. When needed, glassware was dried overnight in an oven $\left(T>100^{\circ} \mathrm{C}\right)$. 


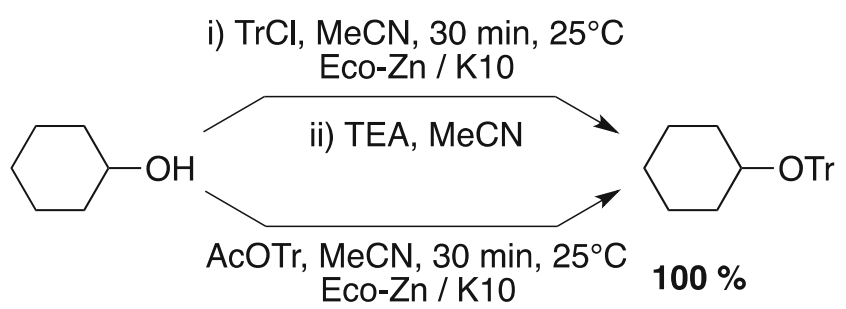

Scheme 1 Tritylation of cyclohexanol by Eco-Zn catalyst

\section{Purification and analysis of reaction products}

Gas chromatography coupled with mass spectrometry (GCMS) analyses were performed using electronic impact ionization mode on a Varian Saturn 2000 ion trap instrument, interfaced with a Varian CP-3800 apparatus. The Varian CP3800 was equipped with a 1079 split-splitless injector $\left(206^{\circ} \mathrm{C}\right)$ and a $30 \mathrm{~m} \times 0.25 \mathrm{~mm} \times 0.25 \mu \mathrm{m}$ film thickness ID WCOT CPSil-8CB fused silica capillary column (Chrompack ${ }^{\circledR}$, Bergen op Zoom, The Netherlands), with helium as carrier gas ( $1 \mathrm{~mL} / \mathrm{min})$, and was programmed for 2 min isothermal at $50{ }^{\circ} \mathrm{C}$, which was then increased from 50 to $220{ }^{\circ} \mathrm{C}$ at $4{ }^{\circ} \mathrm{C} / \mathrm{min}$. Mass spectra were recorded in electronic impact (EI) at $70 \mathrm{eV}$ and were identified by comparison with data of the NIST 98 software library (Varian, Palo Alto, CA, USA) and by comparison of the retention time of the standard compounds.

Flash column chromatography was performed using Chromagel Carlo Erba Reactifs SDS silica 60 A CC 35$70 \mu \mathrm{m}$. Reactions were monitored using Merck Kieselgel 60 F254 aluminum. TLCs were visualized by UV fluorescence $(254 \mathrm{~nm})$, and then one of the following: $\mathrm{KMnO}_{4}$, ninhydrin, phosphomolybdic acid solution, and phosphotungstic acid solution was used.

NMR spectra were recorded on a Brüker Avance 300 spectrometer at room temperature, ${ }^{1} \mathrm{H}$ frequency is at $300 \mathrm{MHz}$, and ${ }^{13} \mathrm{C}$ frequency is at $75 \mathrm{MHz}$. IR spectra were recorded on a PerkinElmer Spectrum 100 FT-IR spectrometer, in ATR mode. Mass spectra were determined with a LC/MS Waters 3695 Separation module, Micromass ZQ 2000 by electrospray ionization (ESI positive or negative). MALDITOF mass spectra were recorded on a Voyager-DE spectrometer (PerSeptive Biosystems, USA) using a 10:1 $(\mathrm{m} / \mathrm{m}) \mathrm{mix}-$ ture of 2,4,6-trihydroxyacetophenone/ammonium citrate as a saturated solution in acetonitrile/water $(1: 1, v / v)$ for the matrix. The structure of compounds was determined by full spectroscopic characterization and was identified by comparison to previously published spectral data.

\section{Protection of alcohol groups}

Tritylation Eco-Zn catalyst was obtained through the process described above. Montmorillonite K10 was obtained from
Alfa-Aesar. In a typical experiment, montmorillonite K10 $(170 \mathrm{mg})$ was placed in a porcelain mortar and air-dried. Eco-Zn ( 0.58 equiv., $0.58 \mathrm{mmol} \mathrm{Zn}$ (II)) was added and mixed with montmorillonite K10 using a pestle to obtain a homogeneous powder. This powder was then put in a dry roundbottom flask in which nucleophilic substrate (1 equiv., $1 \mathrm{mmol}$ ), and trityl chloride (1 equiv., $1 \mathrm{mmol}, 278.8 \mathrm{mg}$ ) was then added. The suspension was allowed to stir for $1 \mathrm{~h}$. The catalyst was then separated by filtration, and the reaction mixture was concentrated under reduced pressure. Taken up with dichloromethane, the organic phase was washed with water. After drying and concentrating the organic phase, the product obtained was analyzed by IR and GC-MS. Menthol was used as an internal reference, and it was confirmed that the reaction was quantitative. IR spectra were recorded on a PerkinElmer Spectrum 100 FT-IR spectrometer, in ATR mode.

Acetylation In a typical procedure, the nucleophilic substrate (1 equiv., $1 \mathrm{mmol}$ ) was placed in a $10-\mathrm{mL}$ flask equipped with a magnetic stirring bar. Acetic anhydride (1.2 equiv., $1.2 \mathrm{mmol}, 122.51 \mathrm{mg}$ ) diluted in $10 \mathrm{~mL}$ of acetonitrile was added. The silica-supported Eco-Zn catalyst ( $94 \mathrm{mg}$ of finely divided ecocatalyst in the presence of $170 \mathrm{mg}$ of $\mathrm{SiO}_{2}$, dried by heating on an electric lamp for $15 \mathrm{~min}$ at $150^{\circ} \mathrm{C}$ ) was then introduced to the mixture. The reaction was complete in $3 \mathrm{~h}$ at $80^{\circ} \mathrm{C}$. The reaction mixture was filtered, and the catalyst was isolated and dried for subsequent reaction. The filtrate was diluted in an organic solvent such as dichloromethane, washed with diluted sodium bicarbonate solution, and then dried and concentrated under reduced pressure. IR followed by GC-MS confirmed the quantitative formation and purity of acetylation products.

Silylation Eco-Zn (0.12 equiv., $0.12 \mathrm{mmol} \mathrm{Zn}$ (II), $47 \mathrm{mg}$ ) was dried prior to the reaction and supported on $\mathrm{SiO}_{2}(170 \mathrm{mg})$ in the typical procedure stated before. Alcohol (1 equiv., $1 \mathrm{mmol}$ ) and hexamethyldisilazane (HMDS) ( 0.75 equiv., $0.75 \mathrm{mmol}$, $120.15 \mathrm{mg}$ ) were added under $\mathrm{N}_{2}$ at $25^{\circ} \mathrm{C}$, to a suspension of $2 \mathrm{~mL}$ of anhydrous acetonitrile with the supported ecocatalyst. With the polyol derivatives, the ratio $\mathrm{OH}$ moiety/HMDS was 1:0.75. The mixture was stirred and was then filtered to recover the ecocatalyst, washed with EtOAc and concentrated under reduced pressure. The products were confirmed by IR and GC-MS and compared with spectra of authentic samples.

Recycling of the Eco-Zn catalyst After completion of the reaction, the supported catalyst was filtered, washed twice with dichloromethane, and easily dried by heating at $110^{\circ} \mathrm{C}$ for $30 \mathrm{~min}$. The solid residue was kept in a stove at $90^{\circ} \mathrm{C}$. It was reused as ecocatalyst under the same conditions and retained optimum activity until 4 cycles. The batch-to-batch variability of reagent was controlled by ICP-MS. 


\section{$\mathrm{Ac}_{2} \mathrm{O}$ \\ $\mathrm{R}-\mathrm{OH} \underset{\mathrm{CH}_{3} \mathrm{CN} 80^{\circ} \mathrm{C}}{\stackrel{\mathrm{Eco}-\mathrm{Zn} / \mathrm{SIO}_{2}}{\longrightarrow}} \mathrm{R}-\mathrm{OAc}$}

Scheme 2 Acetylation of alcohol by Eco-Zn catalyst

\section{Protection of the carbonyl group}

Enol ether formation In a $25-\mathrm{mL}$ flask equipped with a magnetic stirrer, a condenser, a dropping funnel, and a thermometer, $5 \mathrm{~mL}$ of absolute ethanol and Eco-Mn catalyst (0.30 mmol in $\mathrm{Mn}(\mathrm{II}), 286 \mathrm{mg}$ ) were added. Citronellal ( $3.0 \mathrm{mmol}, 462 \mathrm{mg}$ ) was introduced on the mixture. After stirring and heating for $6 \mathrm{~h}$, the reaction was complete. The reaction products have been characterized easily by GC-MS and IR.

Dithioacetal deprotection The dithioacetal substrate $(0.1$ equiv., $0.1 \mathrm{mmol}, 28.64 \mathrm{mg}$ ) was introduced with $6 \mathrm{~mL}$ of acetonitrile in a $10-\mathrm{mL}$ flask equipped with a magnetic stirring bar. Four hundred milligrams of finely ground Eco-Tl catalyst was introduced to the mixture. The reaction was stirred for $22 \mathrm{~h}$ at room temperature. The product was directly silylated to be analyzed by GC-MS. The procedure described above with Eco-Zn was followed for silylation. The reaction mixture was filtered and concentrated under reduced pressure. The crude product was analyzed by ${ }^{1} \mathrm{H},{ }^{13} \mathrm{C}$, COSY, HSQC, and HMBC NMR. The persilylated glucose was obtained as the two anomers, $\alpha$ and $\beta$, easily identifiable by ${ }^{1} \mathrm{H}$ NMR: two doublets, respectively, 5.7 and $5.5 \mathrm{ppm}$ in the ratio 66:33.

\section{Protection of the carboxyl group}

Transesterification The reaction was conducted in a $10-\mathrm{mL}$ sealed tube, equipped with a magnetic stirring bar, under $\mathrm{N}_{2}$ atmosphere. To a solution of ethyl-2-methyl-5-[(1S,2R)-1,2,3trihydroxypropyl]-3-furanoate (1 equiv., $0.041 \mathrm{mmol}, 10 \mathrm{mg}$ ) in hexan-1-ol (2 mL), Eco-Zn (0.1 equiv., $0.0041 \mathrm{mmol}$ $\mathrm{Zn}(\mathrm{II}), 4.1 \mathrm{mg}$ ) was added. The mixture was heated for $16 \mathrm{~h}$ at $80{ }^{\circ} \mathrm{C}$. The reaction was monitored by TLC with cyclohexane/acetone (9:1). After completion of the reaction, the crude product was purified by column chromatography over silica gel using cyclohexane/acetone $(9: 1)$ as the eluent, to afford pure hexyl-2-methyl-5-[(1S,2R)-1,2,3trihydroxypropyl]-3-furanoate as a yellow oil (12.1 mg, $98 \%$ ). IR 3,444, 2,923, 1,716, and 1,460 cm-1; ${ }^{1} \mathrm{H}$ NMR $\left(\mathrm{CDCl}_{3}, 300 \mathrm{MHz}\right) \delta, 6.62(\mathrm{~s}, 1 \mathrm{H}), 4.22-4.34(\mathrm{~m}, 3 \mathrm{H}), 3.30$ $3.84(\mathrm{~m}, 3 \mathrm{H}), 2.59$ (s, 3H), 1.05-1.50 (m, 8H), 0.88 (m, 3H).

Chemoselective cleavage of carboxylic ester Eco-Ca catalyst (1.8 equiv. $\mathrm{Ca}$ (II), $12.9 \mathrm{mmol}, 3,71 \mathrm{~g}$ ) was added to $16 \mathrm{~mL}$ of a mixture of isopropanol/water $(7: 3 \mathrm{v} / \mathrm{v})$. After $5 \mathrm{~min}$ of stirring, methyl ester (1 equiv., $7.2 \mathrm{mmol}, 0.4 \mathrm{~g}$ ) was slowly added. The reaction mixture was stirred for $3 \mathrm{~h}$ and $30 \mathrm{~min}$ then diluted by addition of $10 \mathrm{~mL}$ of diethyl ether. The $\mathrm{pH}$ was adjusted to 4 by addition of hydrochloric acid solution (1 M), and then, the aqueous layer was extracted with diethyl ether. Organic layers were combined, dried over $\mathrm{MgSO}_{4}$, filtrated, and evaporated under reduced pressure. The residue was purified by column chromatography on silica gel (hexane/ AcOEt 1:1 v/v). A white solid was obtained (80\%). Analyses by ${ }^{1} \mathrm{H}$ and ${ }^{13} \mathrm{C}$ NMR and MS (EI+) of the product were consistent with Escande et al. (2013) and clearly proved the formation of the expected acid.

\section{Protection of the amino group}

N-Formylation Eco-Zn catalyst (1 equiv. $\mathrm{Zn}(\mathrm{II}), 1 \mathrm{~g})$ and silica (1 equiv., $1 \mathrm{~g}$ ) were stirred in ethanol for $1 \mathrm{~h}$ at room temperature. The solvent was evaporated, and the collected powder was dried in a stove at $130{ }^{\circ} \mathrm{C}$ overnight and stored in a desiccator. Amine (1 equiv., $0.2 \mathrm{mmol}$ ), formic acid (4 equiv., $0.8 \mathrm{mmol}$ ), and $100 \mathrm{mg}$ of silica-supported Eco-Zn catalyst $(0.04 \mathrm{mmol} \mathrm{Zn}(\mathrm{II}))$ were stirred for $4 \mathrm{~h}$ at $110^{\circ} \mathrm{C}$ in a

Table 2 Acetylation of alcohol function by Eco-Zn catalyst

\begin{tabular}{ccc} 
Substrate & Conditions (h) & Yield (\%) \\
\hline
\end{tabular}


Table 3 Acetylation of carbohydrate derivatives and polyols by Eco-Zn catalyst

Entry

$10-\mathrm{mL}$ sealed tube. The reaction was monitored by IR and GC-MS analysis. All the products were characterized by NMR, IR, and MS (EI+) and compared with literature (Bao et al. 2008; Brahmachari and Lasakr 2010; Das et al. 2008; Ma'mani et al. 2010; Saladino et al. 2006; Shekhar et al. 2009; Suchý et al. 2011).

Cleavage of the tert-butyloxycarbonyl group To a solution of $N$-tert-butyloxycarbonyl (BOC)-L-alanine-benzylester (1 equiv., $0.19 \mathrm{mmol}, 55 \mathrm{mg}$ ) in $1 \mathrm{~mL}$ of $\mathrm{MeOH}$, Eco-Zn catalyst ( 1 equiv. Zn(II), $0.19 \mathrm{mmol}, 214 \mathrm{mg}$ ) was added. The resulting suspension was stirred for $5 \mathrm{~h}$ at $50{ }^{\circ} \mathrm{C}$. The reaction was monitored by TLC with cyclohexane/ethyl acetate (7:3). After completion of the reaction, the crude product was filtered and concentrated under reduced pressure to afford L-alaninebenzylester $(100 \%)$. Analyses by ${ }^{1} \mathrm{H}$ and MS (EI+) of the product were consistent with literature.

\section{Results and discussion}

Protection of the hydroxyl group

A wide range of natural products is characterized by the presence of carbohydrate entities. Natural carbohydrates and synthetic analogues are playing a decisive role in the area of the pharmaceutical, nutraceutical, cosmetic, and energy industries. In synthetic strategy, carbohydrates are particularly attractive substrates, because there are a high degree of functionality and chirality. The synthetic potential of carbohydrates is closely linked to the ability to realize chemoselective transformations of functional groups. However, a scaffold of protecting groups is always required for such transformations.
For the first time, new bio-based strategies are presented for diverse protections of hydroxyl groups including diols.

\section{Formation}

Tritylation The triphenylmethyl or trityl group (abbreviated OTr) has been extensively used in classical carbohydrate chemistry. Its stability to bases and nucleophiles, but its easy removal under acidic conditions has often been appreciated.

Two methods for the introduction of the trityl group have been studied: the direct tritylation with trityl chloride and the transtritylation. Ecocatalysis-Zn, called Eco-Zn, was a biobased catalytic system, derived from the zinchyperaccumulating plant, $N$. caerulescens, which was used in both reaction types. Cyclohexanol has been used as a model substrate (Scheme 1).

The two processes were performed with cyclohexanol in a minimum of acetonitrile. The reaction mixture was stirred at room temperature, and it was injected into GC-MS and IR for monitoring progress. The reaction was monitored by GC-MS using menthol as an internal reference. It was quantitative in $1 \mathrm{~h}$ at room temperature. Directly after evaporation and washing for the first reaction, the protected cyclohexanol was obtained pure, with a simple filtration to separate the ecocatalyst resulting in less contamination of the product. Moreover, the Eco-Zn catalyst has been reused several times after thermic treatment at $150^{\circ} \mathrm{C}$.

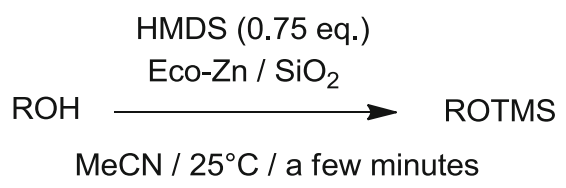

Scheme 3 Silylation of hydroxyl groups by Eco-Zn catalyst 
Table 4 Silylation of hydroxyl groups by Eco-Zn catalyst

\begin{tabular}{|c|c|c|c|c|}
\hline Entry & Substrate & Product & Time & Yield $(\%)$ \\
\hline 1 & & & $15 \mathrm{~min}$ & 100 \\
\hline 2 & & & $\begin{array}{c}15 \\
\min \end{array}$ & 100 \\
\hline 2 & & & $15 \mathrm{~min}$ & 100 \\
\hline 3 & & & $20 \mathrm{~min}$ & 100 \\
\hline 4 & & & $4 \mathrm{~h}$ & 100 \\
\hline 5 & & & $4 \mathrm{~h}$ & 100 \\
\hline 6 & & & $4 \mathrm{~h}$ & 100 \\
\hline 7 & & & $4 \mathrm{~h}$ & 100 \\
\hline 8 & & & $45 \mathrm{~min}$ & 90 \\
\hline & $\mathrm{OH}$ & OTMS & & \\
\hline
\end{tabular}

The classical method for the introduction of the trityl group involves the reaction of a primary alcohol function in pyridine. Long heating, dimethylaminopyridine (DMAP) or diazabicycloundecene (DBU) is often used to accelerate the reaction (Kocienski 1994). These conditions generate high amounts of environmental unfriendly wastes and leads to high E factors. The use of Eco-Zn catalyst substantially reduces wastes at the source.

Lewis acids have been sporadically employed in tritylation protocols. A comparison with zinc chloride homogeneous 

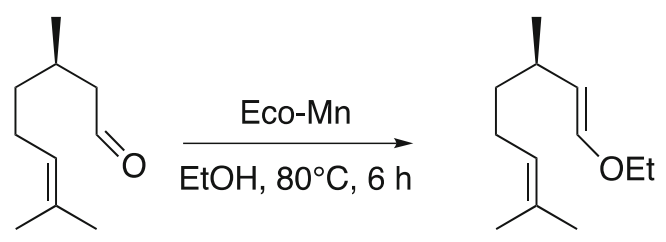

$100 \%$

Scheme 4 Protection of carbonyl groups by Eco-Mn catalyst into enol ether

catalysis and Eco- $\mathrm{Zn}$ is interesting. The use $\mathrm{ZnCl}_{2}$ is based on the use of one equivalent of Lewis acid (Maletese et al. 2011), while 0.1 equivalent of Eco-Zn is sufficient.

The eco-process is thus simple, eco-friendly, and efficient even with secondary alcohol.

Acetylation The acetate ester (abbreviated OAc) is one of the cheapest and most common protections of the hydroxyl groups in oxidation, peptide coupling, or glycosidation reactions. They are easily cleaved under mildly basic or acidic conditions. The formation of a completely acetylated carbohydrate can be obtained by adding acetic anhydride in pyridine solution (Greene and Wuts 1991). This common methodology is efficient but does not respect green and sustainable principles. The toxicity of pyridine and the reaction workup lead to considerable toxic wastes.

The Eco-Zn bio-based polymetallic systems constitute an alternated greener catalyst system for this reaction. Under mild acidic conditions, the acetate ester group of different alcohols was readily prepared by esterification using anhydride acetic acid and Eco-Zn catalyst supported on silica gel (Scheme 2). A simple filtration led to isolate the expected acetylated product. No workup was necessary. As shown in Table 1, $10 \% \mathrm{~mol}$ of $\mathrm{Zn}$ is sufficient to lead to expected quantitative yields. The activity of Eco- $\mathrm{Zn}$ is enhanced with respect reference to commercial $\mathrm{ZnCl}_{2}(24 \% \mathrm{~mol}$ of $\mathrm{Zn}$, Gupta et al. 2008). The polymetallic composition of Eco-Zn allows to avoid the agglomeration of $\mathrm{Zn}$ particles and increases their catalytic activity. Supported Eco-Zn could be completely recovered and recycled in the process after thermic reactivation and without purification. Thus, the use of Eco-Zn as a catalyst offers important advantages in reaction selectivity, efficiency, and waste reduction.

Considering the high yields obtained in the acetylation of model alcohols presented in Table 2, the acetylation of useful carbohydrate derivatives and polyols has been carried out with the same Eco-Zn catalyst (Table 3).
Silylation Trimethylsilyl ethers (abbreviated TMS) are widely used to derivate carbohydrates and polar molecules for GC and GC-MS. TMSCl and TMSOTf are often used but require the presence of amino organic bases and so aqueous workup (Kocienski 1994). A major concern with regard to sustainability is the release of auxiliary substances inducing workup operations and wastes. Thus, the formation of TMS ethers was performed with HMDS and a simple silica-supported biobased catalyst (Scheme 3).

The protection reaction was quantitative and performed at room temperature in a few minutes and with cheap reagents compared to the classical method. Solid catalysts are separated from silylated products by a simple filtration. Products were obtained pure with purification. Trimethylsilylation has been successfully accomplished with a large number of functional groups [primary (entry 1) and secondary alcohols (entry 2), phenol (entry 3), oxime (entry 4), in the presence of ester, dithioacetal, ketone, or trityl groups, with carbohydrates (entries 4-7) and nucleoside (entry 8)]. Excellent results were obtained in each case (Table 4). The efficiency of Eco-Zn catalyst should be noted; the reaction which needed ten times less catalyst than $\mathrm{ZnCl}_{2}$ commercial with the reaction time is similar. The scaling up of the silylation process did not have any problem. It was possible to carry out the silylation of $50 \mathrm{mmol}$ benzylalcohol with the same conditions. In the context of green chemistry, the supported Eco-Zn has been recycled four times without any loss of activity. It was recycled by washing with ethyl acetate and drying in an oven $\left(120^{\circ} \mathrm{C}, 5 \mathrm{~h}\right)$, before being reused in the next run. Subsequent easy workup was based on washing the solid with ethyl acetate in order to extract the reaction products. Insolubility of the metallic elements of the Eco-Zn in this solvent was noted. This improved methodology was very efficient (Table 4, entry 1) and allowed avoiding contamination of reaction products with metallic residue.

Protection of the carbonyl group

\section{Formation}

Ecocatalyst-Mn, called Eco-Mn, is derived from the Mnhyperaccumulating plant, G. exul spp. exul. The conversion of G. exul shoots into ecocatalysts produced Eco-Mn composed of $\mathrm{Mn}(\mathrm{II})$. This oxidation state has been previously investigated (Grison and Escande 2012). It constituted an efficient system for preserving the carbonyl group. The
Scheme 5 Deprotection of $S, S$ acetal of D-glucose by Eco-Tl catalyst

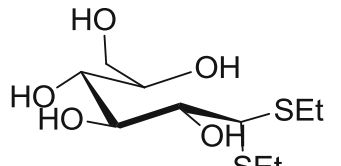

SEt i) $\mathrm{Eco}-\mathrm{Tl}, 25^{\circ} \mathrm{C} 24 \mathrm{~h}$

ii) Eco-Zn, HMDS, $25^{\circ} \mathrm{C}, 1 \mathrm{~h}$

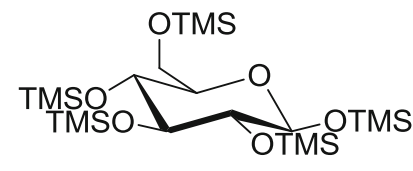

$100 \%$ 
Scheme 6 Transesterification by Eco-Zn catalyst

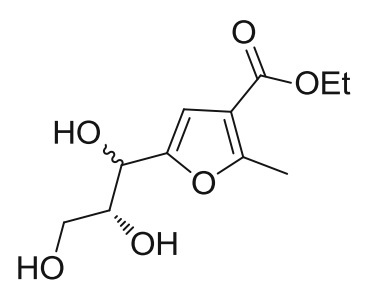

$\underset{\text { 1-hexanol }}{\stackrel{\text { EcoZn }(10 \mathrm{~mol} \% \mathrm{Zn})}{\longrightarrow}}$

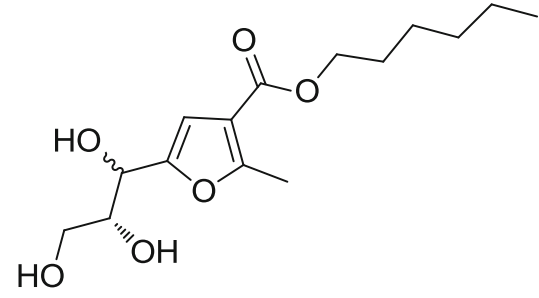

$98 \%$ specific properties of these catalysts are shown in a throughtype reaction (Scheme 4) that consists in the catalyzed acetalization of citronellal following one pot by $\beta$-elimination.

After stirring and heating for $6 \mathrm{~h}$, the expected enol ether was obtained pure with no need of purification. The Eco-Mn was separated from the product by simple filtration. The product purity was easily analyzed by GC-MS and IR.

\section{Cleavage}

The carbohydrate diethyl dithioacetals have been reported as the most frequent acyclic carbohydrate derivatives, because the dithioacetal functionality constitutes the most useful precursor for aldehyde carbohydrates (Horton and Norris 1997). The use of carbohydrate $S, S$-acetals is limited by the severe cleavage conditions of this protection. They are resistant to protic acids; the assistance of heavy metal reagents such as $\mathrm{Ag}(\mathrm{I})$ and $\mathrm{Hg}(\mathrm{II})$ is needed. These at last are remained attached to the dithiol product. The reaction is buffered to neutralize the two equivalents of acid liberated in the hydrolysis. Moreover, long reaction times and heating are required for satisfactory yield. These conditions are difficult to apply to sensitive substrates as carbohydrates without a high loss of yield due to degradation. Oxidative cleavage is an alternative method for dithioacetal deprotection (Horton and Norris 1997). However, it induces rapid degradation when carried on carbohydrates, if the reaction is not carefully controlled.

Jones et al. (1986) have described an effective deprotection of acyclic dithio acetals, ketals, dithiolanes, and dithianes with nitrate thallium. However, this strategy including carbohydrate substrates seems to be unknown. For the first time, the chemoselective cleavage of the diethyl $S, S$-acetal of D-glucose was studied without degradation when using ecocatalyst. Starting with $I$. intermedia, a thallium hyperaccumulating plant, the first Eco-Tl catalyst was prepared and catalyzed the dithioacetalization deprotection of D-glucose derivative (Scheme 5).

The deprotection of $S, S$-acetal $\left(24 \mathrm{~h}, 25{ }^{\circ} \mathrm{C}, 100 \%\right)$ was followed by the silylation of the released anomeric alcohol $\left(1 \mathrm{~h}, 25^{\circ} \mathrm{C}, 100 \%\right)$ to analyze the product.

This result should be noted with interest, because the dithioacetalization of $S, S$-acetal has often been refractory, especially in sensitive substrates, such as carbohydrates. This result represents an efficient alternative to classic procedures.

Protection of the carboxyl group

\section{Formation}

The natural or synthetic carboxy functions are usually an ester. Small esters, in combination with other volatile compounds, play an important role in insect communication and produce the pleasant aroma of fruits. They are the major components of most flavors and fragrances (Marsili 2002). Their use represents an increasing market. Moreover, a combination between a high-ester and a carbohydrate is a common and useful strategy.

Therefore, Eco-Zn catalyst was tested to catalyze the formation of an ester nonionic surfactant.

Recently, our group reported the use of Eco-Zn catalyst for the Garcia Gonzalez reaction, an innovation that is of major interest for the conversion carbohydrates from biomass into polyhydroxylalkylfuran (Escande et al. 2014). Here, the Eco-Zn catalyst was used to catalyze the transesterification of the ethyl polyhydroxylalkylfuran into hexyl polyhydroxylalkylfuran which represents a model of bio-based nonionic surfactant (Scheme 6).

1-Hexanol has been chosen as a model reagent for the transesterification. It was used both as a reagent and as a solvent. The reaction mixture was heated for $16 \mathrm{~h}$ at $80^{\circ} \mathrm{C}$.
Scheme 7 Selective deprotection of carboxyl group without the cleavage of Fmoc with Ca-Eco Catalyst
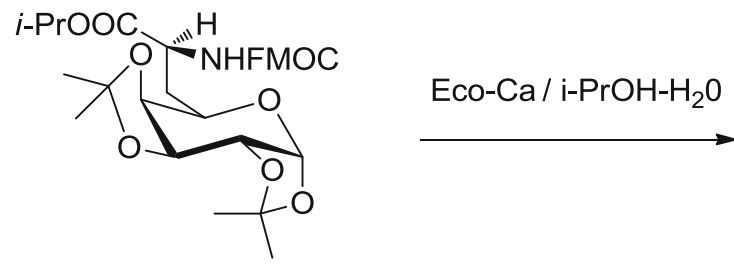

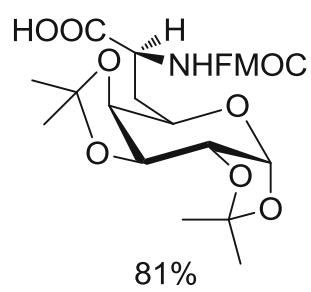


<smiles>Nc1ccccc1</smiles>

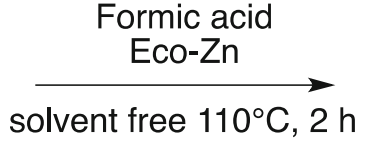<smiles>O=CNc1ccccc1</smiles>

Scheme $8 N$-Formylation of aniline

After purification by flash chromatography, the expected product was obtained with high yield and the structure was confirmed by IR and ${ }^{1} \mathrm{H}$ NMR. The regioselectivity of this result should be noted, given the presence of the polyol moiety.

\section{Cleavage}

The 9-fluorenylmethoxycarbonyl (Fmoc) group is often applied as a temporary protecting group in peptide synthesis, because it is very stable to acidic reagents. It is a widely applied alternative to the $\mathrm{Bzl} / \mathrm{BOC}$ protecting group. However, it is cleaved easily under mildly basic conditions by basecatalyzed elimination. Secondary amine (piperidine, diethylamine), DBU, fluoride ions attack Fmoc group at room temperature. Fmoc group is not compatible with saponification standard conditions of $\mathrm{C}$-terminal esters or linkers.

Table $5 \mathrm{~N}$-Formylation of aniline

\begin{tabular}{|c|c|c|c|}
\hline Entry & Product & $\begin{array}{l}\text { Experimental } \\
\text { conditions }\end{array}$ & Yield (\%) \\
\hline 1 & & Eco-Zn catalyst (Zn $20 \%$ ) & 90 \\
\hline 2 & & $\begin{array}{l}\text { Eco-Zn catalyst (Zn } 20 \%)-K 10 \\
(1: 1)\end{array}$ & 91 \\
\hline 3 & & $\begin{array}{l}\text { Eco-Zn catalyst }(\mathrm{Zn} 20 \%)-\mathrm{SiO}_{2} \\
(1: 1)\end{array}$ & 95 \\
\hline 4 & & $\begin{array}{l}\mathrm{ZnCl} / 2 / 70{ }^{\circ} \mathrm{C} \text { (Chandra Shekdar } \\
\text { et al. 2009) }\end{array}$ & 96 \\
\hline 5 & & $\begin{array}{l}\text { Imidazole / DMF } / 120{ }^{\circ} \mathrm{C} \text { (Suchy } \\
\text { et al. 2011) }\end{array}$ & 98 \\
\hline 6 & & $\mathrm{Cu}(\mathrm{II})-\mathrm{H}_{2} \mathrm{O}_{2}$ (Tumma et al. 2009) & 75 \\
\hline 7 & & $\mathrm{SiO}_{2} / 2 \mathrm{~h} / 110^{\circ} \mathrm{C}$ & 83 \\
\hline 8 & & $-\quad / 2 \mathrm{~h} / 110^{\circ} \mathrm{C}$ & 75 \\
\hline
\end{tabular}


Table $6 N$-Formylation of amines

\begin{tabular}{|c|c|c|c|}
\hline Entry & Product & $\begin{array}{l}\text { Experimental } \\
\text { conditions }\end{array}$ & Yield \\
\hline 9 & & $\begin{array}{l}\text { Eco-Zn catalyst }(20 \% \mathrm{Zn})-\mathrm{SiO}_{2} \\
(1: 1) \\
110^{\circ} \mathrm{C}-4 \mathrm{~h}\end{array}$ & 100 \\
\hline 10 & & $\begin{array}{l}\mathrm{ZnCl}_{2} \text { (Chandra Shekdar et al. } \\
\text { 2009) }\end{array}$ & 60 \\
\hline 11 & & $\mathrm{Cu}(\mathrm{II})$ (Tumma et al. 2009) & 70 \\
\hline 12 & & $\begin{array}{l}\text { Eco-Zn catalyst }(20 \% \mathrm{Zn})-\mathrm{SiO}_{2} \\
(1: 1) \\
110^{\circ} \mathrm{C}-4 \mathrm{~h}\end{array}$ & 100 \\
\hline 13 & & $\begin{array}{l}\mathrm{ZnCl}_{2} \text { (Chandra Shekdar et al. } \\
\text { 2009) }\end{array}$ & 60 \\
\hline 14 & & $\begin{array}{l}\text { Eco-Zn catalyst }(20 \% \mathrm{Zn})-\mathrm{SiO}_{2} \\
(1: 1) \\
110^{\circ} \mathrm{C}-4 \mathrm{~h}\end{array}$ & 50 \\
\hline 15 & & $\begin{array}{l}\text { No catalyst } \\
110^{\circ} \mathrm{C}-4 \mathrm{~h}\end{array}$ & 19 \\
\hline 16 & & $\begin{array}{l}\text { Eco-Zn catalyst }(20 \% \mathrm{Zn})-\mathrm{SiO}_{2} \\
(1: 1) \\
110^{\circ} \mathrm{C}-4 \mathrm{~h}\end{array}$ & 100 \\
\hline 17 & & $\begin{array}{l}\text { Eco-Zn catalyst }(20 \% \mathrm{Zn})-\mathrm{SiO}_{2} \\
(1: 1) \\
110^{\circ} \mathrm{C}-4 \mathrm{~h}\end{array}$ & 98 \\
\hline 18 & & $\begin{array}{l}\text { Eco-Zn catalyst }(20 \% \mathrm{Zn})-\mathrm{SiO}_{2} \\
(1: 1) \\
110^{\circ} \mathrm{C}-4 \mathrm{~h}\end{array}$ & 90 \\
\hline 19 & & $\begin{array}{l}\text { Eco-Zn catalyst }(20 \% \mathrm{Zn})-\mathrm{SiO}_{2} \\
(1: 1) \\
110^{\circ} \mathrm{C}-4 \mathrm{~h}\end{array}$ & 100 \\
\hline 20 & & $\begin{array}{l}\text { Benzimidazolin-2-stannylene } \\
\text { (Hahn et al. 2007) }\end{array}$ & 91 \\
\hline
\end{tabular}




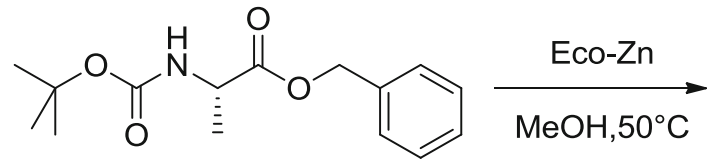

$\mathrm{MeOH}, 50^{\circ} \mathrm{C}$<smiles>C[C@H](N)C(=O)OCc1ccccc1</smiles>

$100 \%$
However, $\mathrm{CaCl}_{2}$ addition has been reported to allow the chemoselective cleavage of simple ester in the presence of Fmoc group (Pascal and Sola 1998).

Eco-Ca catalyst derived from the Ca-hyperaccumulating plant, P. major, a bio-based catalyst, could be an excellent alternative to Pascal and Sola conditions (Scheme 7). The Ca cation strengthened the electrophilicity of the carbonyl moiety in the ester group. The controlled addition of $\mathrm{NaOH}(1 \mathrm{M})$ until $\mathrm{pH} 4$ allowed the partial hydrolysis of bio-based $\mathrm{CaCl}_{2}$. In these conditions, the chemoselective hydrolysis of the methyl ester of 6,7-dideoxy-1,2/3,4-di-O-isopropylidine7-[(9-fluorenylmethoxycarbonyl)amino]-D-glycero- $\alpha$-Dgalacto-octopyranuronic methyl ester was observed without the cleavage of the base labile Fmoc. After workup, the obtained residue is purified by column chromatography on silica gel. The expected galactosyl amino acid was obtained with $81 \%$ yield.

We have applied the same conditions of Pascal and Sola for the reaction and obtained similar yields. Therefore Eco-Ca catalyst is as efficient as the commercial catalyst of Pascal and Sola, and the Eco-Ca catalyst is bio-sourced, which is a major principle of green chemistry. When compared to our previous procedure (Escande et al. 2013a), the present strategy is more advantageous as the ecocatalyst, namely Eco-Ca, and is easily available.

Protection of the amino group

\section{Formation}

$\mathrm{N}$-Formylation is a bio-inspired protection of the amino group for the protection of amino acids.

Carboxamide-type protecting groups have been considered as a valuable alternative to the Fmoc group. Mainly, the formyl group has been used, because it is cleavable by specific and different conditions, solvolysis, oxidation, or hydrazinolysis. $N$-Formylation is also often suggested as a protection of the indole ring of tryptophan. Formamides have wide applications as intermediates in the preparation of pharmaceuticals and reagents for Vilsmeier formylation (Chen et al. 2000; Dowie et al. 1993). Formylation of amines is often based on the uses of expensive and difficult accessibility reagents. Yields are poor, because side products are observed (Das et al. 2008; Greene and Wuts 1991). Recently, Shekar et al. (2009) have described a new synthetic method using
$\mathrm{ZnCl}_{2}$ as a catalyst under solvent-free condition and without support. This prompted us to study this reaction with Eco-Zn.

Interestingly, Eco-Zn catalysts have also been successfully applied to $N$-formylation (Scheme 8 and Table 5). The reaction of aniline and formic acid with Eco-Zn catalyst gave the corresponding $N$-formylaniline in $90 \%$ yield (entry 1 ). Under the identical conditions, $\mathrm{N}$-formylation was promoted also with supported Eco-Zn catalyst on montmorillonite K10 (entry 2) or $\mathrm{SiO}_{2}$ (entry 3). Ecocatalysts were even more efficient (91 and $95 \%$ ) and were easily separated from products. These results can be compared favorably with $\mathrm{ZnCl}_{2}$-catalyzed $\mathrm{N}$ formylation (Shekar et al. 2009), on silica gel (entry 7) or without catalyst (entry 8).

We described the development of the first supported $N$ formylation. It is very interesting in the area of bio-based chemistry. It offers several advantages such as clean reaction, easy separation of the ecocatalyst, no aggregation of catalytic particles, and best activity. The supported Eco-Zn has been also recycled four times without any loss of activity.

This has encouraged us to extend the $\mathrm{N}$-formylation to a variety of amines. The results are summarized in Table 6 .

Similar results were obtained with primary aliphatic amines (entries 9 and 16), which hindered secondary aliphatic (entry 14) or cyclic amines (entry 12). Multifunctional substrates such as amino alcohol (entry 8), amino acid (entry 12), and diamines (entry 13) have been $N$-formylated effectively. Eco$\mathrm{Zn}$ catalyst gets significantly highest yields (entries 9, 12, 14, and 19) than those obtained without catalyst (entry 15) or with classical catalysts (entries 10, 11, 13, and 20). Thus, Eco-Zncatalyzed $N$-formylation is a general and convenient procedure.

\section{Cleavage}

BOC protecting group is one of the most common protecting groups for amine in peptidic synthesis. Removal of BOC is accomplished by with strong acids such as trifluoroacetic acid in dichloromethane or $\mathrm{HCl}$ or $\mathrm{HBr}$ in methanol. Eco-Zn was used as an alternative method in mild and selective conditions

Table $7 \mathrm{~N}$-BOC cleavage

\begin{tabular}{lll}
\hline Entry & Experimental conditions & Yield (\%) \\
\hline 1 & Eco-Zn (0.1 equiv.), 3 days & 0 \\
2 & Eco-Zn (1 equiv.), 5 h & 100 \\
\hline
\end{tabular}


to cleave $\mathrm{BOC}$ protecting group in presence of a benzyl ester group (Scheme 9). We can conclude that the treatment of a peptide protected with $\mathrm{N}$-BOC/COO-Bn protecting groups would deprotect only the $\alpha$-amino terminus, whilst the $\mathrm{C}$ terminus would remain protected. Deprotecting group of $\mathrm{N}$ BOC needed one equivalent of $\mathrm{Zn}$ (Table 7). Mutually, the trityl group could be introduced with 0.6 equiv. of Eco-Zn, whilst the deprotection of $N$-BOC would be avoided.

\section{Conclusion}

The ecocatalysis represents a catalytic, eco-friendly, and efficient concept to promote protection or deprotection reactions. It has a proven potential for various applications such as the protection of hydroxyl groups by tritylation, silylation, and acetylation; protection of carbonyl groups in the form of the enol ether and transesterification; and protection of amino groups by $N$-formylation. Cleavage of dithioacetal and carboxylic acid is excellent and proceeds with promising chemoselectivity. In addition, these methods can be generalized as complex and natural substrates.

In conclusion, ecocatalysts derived from metalhyperaccumulating plants still represent a rich and varied strategy for sustainable chemistry. Phytoremediation and organic synthesis will be doubtless a fruitful and long-standing combination for the environment.

Acknowledgments The authors would like to thank the Agence Nationale de la Recherche (ANR 11ECOT 011 01), Centre National de la Recherche Scientifique (CNRS), Agence de l'Environnement et de la Maîtrise de l'Energie (ADEME), and Fond Européen de Développement Régional (FEDER) program for their financial supports.

\section{References}

Bao K. Zhang W. Bu X. Song Z. Zhang L. Cheng M. (2008). A novel type of $\mathrm{N}$-formylation and related reactions of amines via cyanides and esters as formylating agents. Chem Commun 5429-5431

Brahmachari G, Lasakr S (2010) A very simple and highly efficient procedure for $\mathrm{N}$-formylation of primary and secondary amines at room temperature under solvent-free conditions. Tetrahedron Lett 51:2319-2322

Chandra Shekhar A, Ravi Kumar A, Sathaiah G, Luke Paul G, Madabhushi Sridhar V, Shanthan Rao P (2009) Facile $N$-formylation of amines using lewis acids as novel catalysts. Tetrahedron Lett 50: 7099-7101

Chen BC, Bendarz MS, Zhao R, Sundee JE, Chen P, Shen Z, Skoumbourdis AP, Barrish JC (2000) A new facile method for the synthesis of 1-arylimidazole-5-carboxylates. Tetrahedron Lett 41 : 5453-5456

Das B, Krishnaiah M, Balasubramanyam P, Veeranjaneyulu B, Kumar DN (2008) A remarkably simple $N$-formylation of anilines using polyethylene glycol. Tetrahedron Lett 49:2225-2227
Dowie IM, Earle MJ, Heaney H, Shuhaibar KF (1993) Vilsmeier formylation and glyoxylation reactions of nucleophilic aromatic compounds using pyrophosphoryl chloride. Tetrahedron 49:40154034

Escande V, Garoux L, Grison C et al (2013a) Ecological catalysis and phytoextraction: symbiosis for future. Appl Catal B Environ. doi:10. 1016/j.apcatb.2013.04.011

Escande V, Olszewski TK, Grison C (2013b) Preparation of ecological catalysts derived from $\mathrm{Zn}$ hyperaccumulating plants and their catalytic activity in Diels-Alder reaction. C R Chim. doi:10.1016/j.crci. 2013.09.009

Escande V, Olszewski TK, Petit E, Grison C (2014) Biosourced polymetallic catalysts: an efficient means to synthesize underexploited platform molecules from carbohydrates. ChemSusChem. doi:10.1002/cssc. 201400078

Greene TW, Wuts PGM (1991) Protective groups in organic synthesis. Wiley, New York

Grison C. Escande V (2012). Use of certain manganese-accumulating plants for carrying out organic chemistry reactions. WO 2014/ 016509 A1.

Grison C. Escande V (2013). Use of certain metal-accumulating plants for implementing organic chemistry reactions. WO 2013150197 A1

Grison C. Escande V. (2014). Use of particular metal accumulating plants for implementing catalyzed chemical reactions PCT/EP2014/ 053485

Grison C. Escarre J. (2011). Use of plant/its part having accumulated at least one metal having zinc, nickel or copper to prepare composition having a metal catalyst for allowing the implementation of organic synthesis reactions e.g. halogenation of alcohols. WO2011064462A1

Grison CM, Escande V, Petit E, Garoux L, Boulanger C, Grison C (2013) Psychotria douarrei and Geissois pruinosa, novel resources for the plant-based catalytic chemistry. Rsc Adv 3: 22340-22345

Gupta R, Kumar V, Gupta M, Paul S, Gupta R (2008) Silica supported zinc chloride acetylation of amines alcohols and phenols. Indian $\mathrm{J}$ Chem 47B:1739-1743

Hahn FE, Wittenbecher L, Le Van D, Zabula AV (2007) Benzimidazolin2-stannylenes with $N, N^{\prime}$-alkyl (Me and Et) and Lewis base functional groups. Inorg Chem 46:7662-7667

Horton S. Norris P. (1997). Preparative carbohydrate chemistry (Ed. Hanessian S.), Marcel Dekker, Inc., New York Basel.

Jones PS, Ley SV, Simpinks NS, Whittle AJ (1986) Total synthesis of the insect antifeedant ajugarin I and degradation studies of related clerodane diterpenes. Tetrahedron 42:6519-6534

Kocienski PJ (1994) In: Enders D, Noyori R, Trost BM (eds) Protecting groups, Thieme Foundations of Organic Chemistry Series. Georg Thiem Verlag Stuttgart, New York

Losfeld G, Vidal De La Blache P, Escande V, Grison C (2012a) Zinc hyperaccumulating plants as renewable resources for the chlorination process of alcohols. Green Chem Lett Rev 5: 451-456

Losfeld G, Escande V, Vidal De La Blache P, L'Huillier L, Grison C (2012b) Design and performance of supported Lewis acid catalysts derived from metal contaminated biomass for friedel-crafts alkylation and acylation. Catal Today 189:111-116

Losfeld G, Escande V, Jaffré T, L'Huillier L, Grison C (2012c) The chemical exploitation of nickel phytoextraction: an environmental, ecologic and economic opportunity for New Caledonia. Chemosphere 89:907-910

Ma'mani L, Sheykhan M, Heydari A et al (2010) Sulfonic acid supported on hydroxyapatite-encapsulated- $\gamma-\mathrm{Fe}_{2} \mathrm{O}_{3}$ nanocrystallites as a magnetically Brønsted acid for $\mathrm{N}$-formylation of amines. Appl Catal Gen 377:64-69 
Maletese M, Vergari MC, Donzello MP (2011) Zinc chloride homogeneous catalysis in the tritylation of hydroxyl- and amide-bearing molecules. Tetrahedron Lett 52:483-487

Marsili R (2002) Flavor, fragrance, and odor analysis. Marcel Dekker, New York

Pascal R, Sola R (1998) Preservation of the protective group under alkaline conditions by using $\mathrm{CaCl}_{2}$. Applications in peptide synthesis. Tetrahedron Lett 39:5031-5034

Saladino R, Crestini C, Neri V et al (2006) Origin of informational polymers: the concurrent roles of formamide and phosphates. ChemBioChem 7:1707-1714
Shekar AC, Kumar AR, Sathaiah G, Paul L, Sridhar M, Rao PS (2009) Facile $N$-formylation of amines using Lewis acids as novel catalysts. Tetrahedron Lett 50:7099-7101

Suchý M, Elmehriki AAH, Hudson RHE (2011) A remarkably simple protocol for the $\mathrm{N}$-formylation of amino acid esters and primary amines. Org Lett 13:3952-3955

Tumma H, Nagaraju N, Reddy KV (2009) A facile method for the $N$-formylation of primary and secondary amines by liquid phase oxidation of methanol in the presence of hydrogen peroxide over basic copper hydroxyl salts. J Mol Catal Chem 310: 121-129 